\title{
WORKING GROUP ON PLANETARY SYSTEM NOMENCLATURE (WGPSN)
}

\author{
(GROUPE DE TRAVAIL POUR LA NOMENCLATURE DU SYSTEME \\ PLANETAIRE)
}

\section{CHAIRPERSON: K. Aksnes}

MEMBERS: M. E. Davies, C. de Bergh, M. Ya. Marov, B.G. Marsden, P. Moore, T. C. Owen, V. V. Shevchenko, B. A. Smith

CONSULTANTS: J. Blue, G. A. Burba, L. Gaddis \& P. Masson

\section{ACTIVITIES IN THE LAST TRIENNIUM}

Since July 1996, 815 new names on features on bodies in the Solar System have been assigned by the WGPSN and approved at the IAU General Assembly in Kyoto in 1997. Of these names, 666 were for Venus, 17 for Mars, 3 for the Moon, 125 for the Galilean satellites, 3 for the Uranian satellite Miranda, and 1 for the minor planet Ida. 71 additional names mostly on Venus have been selected and have been given or are awaiting provisional approval by the IAU Executive Committee (EC). These names are up for final approval at the next IAU General Assembly.

The need for all these new names is due to the very successful mapping by the NASA spacecraft Magellan, Galileo, Clementine, Lunar Prospector, Mars Pathfinder, and Mars Global Surveyor. Ground-based observations have lead to the discovery of two additional satellites of Uranus, S/1997 U1 and S/1997 U2, which have been given the provisional names Caliban and Sycorax, respectively.

In addition to having frequent exchanges by means of e-mail, the WG members have also met five times during the triennium: 10 July 1996 in Versailles, France, 17 July 1996 in Birmingham, UK, 20 August 1997 in Kyoto, Japan, 30 November 1997 in Honolulu, Hawaii, and 26-27 October 1998 in Paris, France. The attendance was poor at the first four of these meetings, but the Paris meeting was very well attended with 11 of the $13 \mathrm{WG}$ members being present, plus 6 from the Task Groups that support the WG.

At the Paris meeting many aspects of the WGPSN activity were critically evaluated. A substantial part of the meeting was devoted to a discussion of the need to improve the existing procedures for selecting and approving planetary names. Of special concern is the long time it takes to have the names approved. Usually the need for new nomenclature arises soon after a planetary body has been imaged or a new satellite discovered. With the current practice, names approved by the WGPSN are considered to be provisional and cannot be released and used until they have been approved by the EC which may take many months. While we appreciate our close links with the EC and its interest in nomenclature, we propose to omit this name screening which is a burden on the EC. The WGPSN and its Task Groups have some thirty specialists in astronomy, cartography, and astrogeology most of whom have many years of experience with nomenclature. In the rare event that a name provisionally approved by the WGPSN needs to be revoked, this can be done by a General Assembly which anyway has to give final approval of the names.

The WGPSN is asking for IAU acceptance of the nomenclature procedures, rules, and guidelines listed below. 


\section{NOMENCLATURE PROCEDURES}

1. Proposed nomenclature is the responsibility of the relevant Task Group. Anyone, either scientist or layman, may suggest names for consideration by the Task Group.

2. Names proposed by the Task Group chair or delegate are forwarded to the Working Group for provisional approval.

3. Upon approval by the Working Group, provisional names are published in the electronic Gazetteer of Planetary Nomenclature maintained under WGPSN scrutiny.

4. The provisional names become final when approved by an IAU General Assembly.

\section{NOMENCLATURE RULES AND GUIDELINES}

Names adopted by the IAU must follow various rules and conventions established through the years by the Union. In addition to these general rules and guidelines, more detailed ones will be established for specific planetary bodies as the need arises.

1. Nomenclature is a tool and the first consideration should be to make it simple, clear, and unambiguous. Single names of no more than three syllables are preferred.

2. The number of names chosen for each body should be kept to a minimum and their placement governed by the requirements of the scientific community.

3. Commemoration of persons on planetary bodies should not be a goal in itself but should be reserved for persons of high and enduring international standing. Persons being so honored must have been deceased for at least 3 years.

4. Duplication of the same name on two or more bodies should be avoided. (Prior to the adoption of this rule in 1991, several such duplications did occur).

5. Individual names chosen for each body should be expressed in the language of origin. Transliteration for various alphabets should be given, but there will be no translation from one language to another.

6. Where possible, the themes established in early solar system nomenclature should be used and expanded on.

7. Solar system nomenclature should be international in its choice of names. Recommendations submitted by the IAU national committees will be considered, but final selection of names is the responsibility of the IAU. The WGPSN strongly supports equitable selection of names from ethnic groups/countries on each map; however, a higher percentage of names from the country planning a landing is allowed on landing site maps.

8. No names having political, military or religious significance may be used, except for names of political figures prior to the 19th century.

9. When more than one spelling of a name is extant, the spelling preferred by the person, or used in an authoritative reference, should be used. Diacritical marks are a necessary part of a name and will be used.

10. Ring and ring-gap nomenclature and names of newly discovered satellites are developed in joint deliberation between WGPSN and IAU Commission 20. Names will not be assigned to satellites until their orbital elements are reasonably well known or definite features have been identified on them. 


\section{GAZETTEER OF PLANETARY NOMENCLATURE}

An increasing part of the nomenclature work is being done by e-mail assisted by a website, Gazetteer of Planetary Nomenclature, which has been established at the U.S. Geological Survey, Division for Astrogeology in Flagstaff, Arizona. This website, which is also linked to the IAU website, can be accessed by anyone with the Internet address http://wwwflag.wr.usgs.gov/USGSFlag/Space/nomen/nomen.html. The electronic Gazetteer contains rules and guidelines for the nomenclature and lists all names approved by the IAU, both alphabetically and by feature type. Many images and maps can be viewed. A search engine makes it easy to find details of particular interest.

The electronic Gazetteer of Planetary Nomenclature does not make the printing of new, approved nomenclature in the IAU Transactions superfluous, but the electronic Gazetteer is very useful in that it collects all the names in one place and is updated frequently.

K. Aksnes

Chairperson of the Working Group 